\title{
PAPEL DO JUDICIÁRIO NOS REMANEJAMENTOS DE POPULAÇÕES ATINGIDAS POR HIDRELÉTRICAS NO SUL DO BRASIL
}

Role of the judiciary in the relocation of populations affected by hydroelectric dams in southern Brazil

DOI: $10.30612 /$ re-ufgd.v6i11.8415

Jennifer Azambuja de Morais ${ }^{1}$
Matheus Müller

Recebido: 07/11/2018Ａceito: 03/09/2019

Resumo: A implantação de usinas hidrelétricas significa o realocamento compulsório de famílias ribeirinhas atingidas pelo empreendimento. Muitas famílias já foram desapropriadas em nome de um desenvolvimento econômico, que exige melhor infraestrutura, para a qual a energia elétrica é essencial. A luta pelos direitos humanos e sociais dessas famílias, protagonizada por essas e pelo Movimento dos Atingidos por Barragens, contraria o interesse das empresas responsáveis, bem como o próprio Estado que, mesmo não sendo responsável direto pelos remanejamentos, constitui a Parceria Público Privada para a construção desses grandes empreendimentos. O objetivo central desse trabalho é verificar a atuação do judiciário nesse processo dos remanejamentos dos atingidos por hidrelétricas na bacia do rio Uruguai, no Sul do país, desde a década de 1980.

Palavras Chave: Judiciário, Remanejamentos, Cidadãos Atingidos, Hidrelétricas, Política Pública.

Abstract: The implementation of hydroelectric plants means the compulsory relocation of riverine families affected by the project. Many families have already been expropriated in the name of economic development, which requires better infrastructure, for which electricity is essential. The struggle for the human and social rights of these families, led by them and by the Movement of People Affected by Dams, runs counter to the interests of the responsible companies, as well as the State itself, which, although not directly responsible for relocations, constitutes the Public Private Partnership for construction of these large enterprises. The main objective of this work is to verify the performance of the judiciary in this process of the relocations of those affected by hydroelectric plants in the Uruguay River basin in the south of the country since the 1980s.

Keywords: Judiciary, Remittances, Citizens Affected, Hydroelectric, Public Policy.

\section{Introdução}

No Sul do Brasil, as primeiras iniciativas governamentais para a construção de usinas

1Pós-doutoranda do PPG em Ciência Política da Universidade Federal do Rio Grande do Sul; jennifer.amorais@gmail.com

2Pós-doutorando do PPG em Ciênciais Sociais da Universidade Federal de Santa Maria theusmuller@gmail.com

Moraes \& Muller, p. 55-70 
hidrelétricas (UHEs) foram nos anos 1960, com a contratação de estudos preliminares e a fundação da Eletrosul Centrais Elétricas do Sul S.A. (ELETROSUL), em 1968, companhia estatal responsável pelo setor de produção energética do Sul do país. A ELETROSUL realizou o estudo sobre a possibilidade de construção de UHEs nessa região, e em 1979, publicou o inventário hidroelétrico da bacia do Rio Uruguai, que apresentava a possibilidade de construção de 22 UHEs nacionais nessa bacia, das quais cinco foram construídas até 2013: Itá, Machadinho, Barra Grande, Campos Novos e Foz do Chapecó.

A implantação dessas UHEs ocasiona o deslocamento compulsório de muitas famílias ribeirinhas. Tais famílias necessitam optar por uma das modalidades de remanejamento criadas nestes dois séculos de implantação de UHEs: Indenização em Dinheiro ${ }^{5}$, Reassentamento Rural Coletivo $^{6}$, Pequeno Reassentamento Rural ${ }^{7}$, Carta de Crédito ${ }^{8}$, Reassentamento em Áreas Remanescentes $^{9}$ e Reassentamento Urbano ${ }^{10}$. A opção permanecer em suas terras não existe, mesmo que a população resista, em algum momento o Estado, que não está diretamente ligado aos processos de remanejamento, pode entrar com a ação para uso de bem público e desapropriar essas famílias (MORAIS, 2013). Até mesmo a atuação do Movimento dos Atingidos por Barragens ${ }^{11}$ (MAB), movimento que representa o interesse dos atingidos, que no início era mais ofensiva e contra a construção das UHEs, se adapta a essa situação e se fixa em melhores qualidades de

5 Consiste na aquisição total ou parcial dos bens imóveis atingidos e de áreas remanescentes inviáveis ou de interesse do empreendedor, com pagamento em dinheiro mediante avaliação baseada na ABNT e no TAC.

6 destinado para grupos a partir de 20 famílias, compreende áreas parceladas em lotes rurais individuais de 17 hectares (ha), com infra-estrutura individual e coletiva básica, podendo variar de acordo com a avaliação da propriedade a ser atingida. Nessa modalidade o empreendedor tem a obrigação de prestar assistência técnica através de visitas de técnicos agropecuários e engenheiros agrônomos pelo prazo de cinco anos, além de assistência social através de visitas periódicas de sociólogos e assistentes sociais pelo prazo de 1 ano aos reassentados (ROCHA, 2012, p. 247)

7 Áreas parceladas em lotes rurais individuais com características idênticas ao RRC, destinada para grupos a partir de cinco famílias.

8 Os atingidos são responsáveis pela apresentação de uma área rural ou urbana, que, após vistoria do empreendedor, verificando a adequação do imóvel às características da família, esta poderá ser adquirida através de Carta de Crédito.

9 Relocação em áreas de propriedades que foram adquiridas pelo empreendedor na sua totalidade ou não, que acabam sendo inviabilizadas por estarem em áreas a serem inundadas ou por compreenderem parte da Área de Preservação Permanente (APP).

10 Realocação de atingidos, proprietários ou não, em novo espaço urbano.

11 No dia 24 de abril de 1979, foi formalizada a Comissão Regional de Barragens (CR). Em dezembro de 1983 foi instituída uma Executiva Regional para a liderança do movimento, criando a Comissão Regional de Atingidos por Barragens (CRAB). Em março de 1991, na cidade de Brasília, ocorreu o "I Congresso Nacional dos Atingidos por Barragens", quando se oficializou o Movimento Nacional dos Atingidos por Barragens (MAB). Com isso, a CRAB passou a responder como MAB/Região Sul. 
remanejamento. Avaliando esse processo, o trabalho objetiva analisar o papel de outro ator político nesse processo: o judiciário. Visto que tal ator pode ou não ter influência nesse processo ou ter interferido a favor ou não da população atingida.

O tema se justifica pela existência reduzida de trabalhos na ciência política que verifiquem os impactos de uma UHE na sociedade, menor ainda os que tratam sobre a judicialização desse processo de remanejamentos populacionais. Além disso, apesar da construção de hidrelétricas ter se consolidado nesses dois últimos séculos, o Estado não tem um marco regulatório bem definido para o processo de remanejamento ${ }^{12}$, ficando, significativamente, sob responsabilidade do empreendedor negociar a implantação da UHE com os demais atores envolvidos, com a chancela do Instituto Brasileiro do Meio Ambiente e dos Recursos Naturais Renováveis (IBAMA), viabilizado invariavelmente através de um Termo de Acordo de Conduta ${ }^{13}$ (TAC), existindo então uma prática de remanejamento pelos empreendedores, com o aval do Estado (MORAIS, 2013). Por tais condições, o interesse pelo assunto é justificado, e tem como pressuposto que o judiciário, quando acionado, trabalha em favor dos interesses privados e estatais, não sendo uma alternativa aos cidadãos atingidos contra as desapropriações.

$\mathrm{O}$ artigo está estruturado em três partes. A primeira dedica-se ao conceito de política pública e a intervenção do judiciário na elaboração dessas. A segunda trabalha, de forma muito sucinta, com a construção de UHEs no Brasil, em especial na bacia do rio Uruguai, e o marco regulatório desse processo. $\mathrm{Na}$ última, o artigo traz uma análise da atuação do judiciário no processo de remanejamento de cidadãos atingidos por UHEs na bacia do rio Uruguai.

\section{Políticas Públicas e Judiciário}

12 Existe o Decreto 7.342, de outubro de 2010, no qual consideram-se integrantes da população atingida por empreendimentos hidrelétricos aqueles submetidos aos seguintes impactos: perda de propriedade ou da posse de imóvel localizado no polígono do empreendimento; perda da capacidade produtiva das terras de parcela remanescente de imóvel que faça limite com o polígono do empreendimento e por ele tenha sido parcialmente atingido; perda de áreas de exercício da atividade pesqueira e dos recursos pesqueiros, inviabilizando a atividade extrativa ou produtiva; perda de fontes de renda e trabalho das quais os atingidos dependam economicamente, em virtude da ruptura de vínculo com áreas do polígono do empreendimento; prejuízos comprovados às atividades produtivas locais, com inviabilização de estabelecimento; inviabilização do acesso ou de atividade de manejo dos recursos naturais e pesqueiros localizados nas áreas do polígono do empreendimento, incluindo as terras de domínio público e uso coletivo, afetando a renda, a subsistência e o modo de vida de populações; e prejuízos comprovados às atividades produtivas locais a jusante e a montante do reservatório, afetando a renda, a subsistência e o modo de vida de populações.

13 Segundo Rocha (2009, p.4), “em cada hidrelétrica a ser instalada é previsto o estabelecimento de um Termo de Acordo de Conduta (TAC) entre os agentes sociais envolvidos, que baseado na legislação referida, norteará as negociações sobre esse aspecto da respectiva barragem". 
Não existe um único conceito de políticas públicas ${ }^{14}$, a definição mais conhecida é "governo em ação". Mas quando pensamos em políticas públicas, geralmente, estamos pensando nas ações que o Estado exerce em diversas áreas da sociedade, tais como, educação, saúde, segurança pública, habitação e outras. Sendo uma área da ciência política, as políticas públicas foram adquirindo autonomia e status científico a partir do desdobramento de uma série de análises e estudos acadêmicos realizados desde meados do século XX na Europa e nos EUA, sendo que nesta o enfoque era a ação do governo, como é nos estudos brasileiros, e naquela o objetivo era analisar e explicar o papel do governo e de suas organizações mais importantes na elaboração de políticas públicas (RODRIGUES, 2010, p.29).

Segundo Souza (2006, p. 22), a conjetura analítica que conduziu a constituição e consolidação dos estudos sobre políticas públicas é o de que, “em democracias estáveis, aquilo que o governo faz ou deixa de fazer é passível de ser (a) formulado cientificamente e (b) analisado por pesquisadores independentes".

Não existe uma única, nem melhor, definição sobre o que seja política pública. Mead (1995) a define como um campo dentro do estudo da política que analisa o governo à luz de grandes questões públicas e Lynn (1980), como um conjunto de ações do governo que irão produzir efeitos específicos. Peters (1986) segue o mesmo veio: política pública é a soma das atividades dos governos, que agem diretamente ou através de delegação, e que influenciam a vida dos cidadãos. Dye (1984) sintetiza a definição de política pública como "o que o governo escolhe fazer ou não fazer". A definição ais conhecida continua sendo a de Laswell, ou seja, decisões e análises sobre política pública implicam responder às seguintes questões: quem ganha o quê,por quê e que diferença faz (SOUZA, 2006, p. 24).

De acordo com Lamounier a compreensão do significado das políticas públicas corresponde a um duplo esforço: de um lado entender a dimensão técnico-administrativa que a compõe buscando verificar a eficiência e o resultado prático para a sociedade das políticas públicas; e de outro lado reconhecer que toda política pública é uma forma de intervenção nas relações sociais em que o processo decisório condiciona e é condicionado por interesses e expectativas sociais (apud FERNANDES, s/d, p. 1). Além disso, Lamounier ao analisar alguns determinantes das políticas públicas aponta três elementos fundamentais: “arena decisória, ou seja, a forma na qual

14 “Considera-se que a área de políticas públicas contou com quatro grandes "pais" fundadores: H. Laswell, H. Simon, C. Lindblom e D. Easton. Laswell (1936) introduz a expressão policy analysis (análise de política pública) (...). Simon (1957) introduziu o conceito de racionalidade limitada dos decisores públlicos (policy markers) (...) Lindblom $(1959 ; 1979)$ questionou a ênfase no racionalismo de Laswell e Simon e propôs a incorporação de outras variáveis à formulação e à análise de políticas públicas, tais como as relações de poder e a integração entre as diferentes fases do processo decisório (...). Easton (1965) contribuiu para área ao definir política pública como um sistema, ou seja, como uma relação entre formulação, resultados e o ambiente" (SOUZA, 2006, p. 23 e 24). 
o processo decisório é estabelecido e desenvolvido; o contexto institucional, as influências e os determinantes formais do processo; e o perfil dos atores, incluindo os objetivos e as configurações de poder" (apud ZIMMERMANN, s/d, s/p).

Fazendo uma recapitulação, Rodrigues (2010, p. 52) ressalta que as políticas públicas resultam da atividade política, além disso envolvem mais de uma decisão política e requerem várias ações estratégicas destinadas a implementar objetivos esperados, bem como

Constituem um conjunto articulado de ações, decisões e incentivos que buscam alterar uma realidade em resposta a demandas e interesses envolvidos. Essas ações são desencadeadas por atores que lidam com algum problema público e são desenvolvidas por instituições públicas governamentais pelo processo político (legislativo, judiciário, tribunais de contas, ministério público etc.) que as condicionam. O objetivo é assegurar que o desempenho dessas instituições esteja a serviço do interesse público e submetido ao controle democrático (RODRIGUES, 2010, p. 52 e 53).

Com essas definições de políticas públicas, pode-se resumir política pública como o "Estado em ação". O Estado, segundo Souza (2006, p. 27), possuiria uma autonomia relativa, a qual gera determinadas capacidades, que por sua vez criam as condições para implementação de objetivos de políticas públicas, "a margem dessa "autonomia" e o desenvolvimento dessas "capacidades" dependem, obviamente, de muitos fatores e dos diferentes momentos históricos de cada país".

No Brasil, a partir da década de 1980 , pós o regime militar, o processo de redemocratização do Estado caminhava junto com a descentralização do governo, tanto nos recursos financeiros quanto na prestação de serviços sociais para os estados e os municípios, posteriormente, também houveram as privatizações e as Parcerias Público Privada. Segundo Falleti (2006, p.21), o "processo de descentralização pós-desenvolvimentista aumentou ainda mais os recursos financeiros, a responsabilidade pela formulação de políticas públicas e a autoridade política dos governos subnacionais".

Atualmente, estudos trabalham com o papel do judiciário na formulação de políticas públicas, considerando uma judicialização da política. Taylor (2007) ressalta que o poder judiciário teria um impacto significativo na elaboração das políticas públicas, pois aquela visão de que os tribunais eram apenas instâncias legais vem sem contestada pelo papel político exercido pelo judiciário e sua influencia nas políticas públicas, porém essa nova relação permanece nebulosa no Brasil e na América Latina.

Segundo Castro (2009), esse processo de judicialização da política ocorre porque os 
tribunais são chamados a se pronunciar quando o funcionamento do Legislativo e do Executivo são falhos, insuficientes ou insatisfatórios. Porém, Grinover (2010, p. 13 e 14) ressalta que no Estado democrático de direito, o Judiciário, como forma de expressão do poder estatal, "deve estar alinhado com os escopos do próprio Estado, não se podendo mais falar numa neutralização de sua atividade”. Ao contrário, o Poder Judiciário encontra-se constitucionalmente vinculado à política estatal, para o autor (2010).

Para Castro (2009), essa atuação dos tribunais, no sistema político, vem acontecendo em dois planos: primeiro, o plano das ações políticas ou não jurisdicionais, definidas pelo exercício informal (ou institucionalmente marginal) do poder; e, segundo, o das ações jurisdicionais, caracterizadas pelo exercício formal da autoridade judicial. Conforme o autor:

No primeiro caso, encontram-se pronunciamentos de juízes (discursos de posse, declarações à imprensa) distintos dos que decorrem do exercício da autoridade judicial, mas que são freqüentemente complementares a ela, do ponto de vista político. Por outro lado, as ações jurisdicionais compõem-se de pronunciamentos oficiais dos juízes, no exercício de sua autoridade judicial (despachos, sentenças, votos, acórdãos, decisões liminares) (CASTRO, 2009, s/p).

No entanto, Taylor destaca três dimensões de relevância da atuação do judiciário para a ciência política (segundo o autor podem ser descritas como as dimensões hobbesiana, smithiana e madisoniana): "estas dimensões têm impactos importantes, respectivamente, no monopólio da violência pelo Estado, nas regras de funcionamento da economia e na relação entre os poderes Executivo, Legislativo e Judiciário” (2007, p. 230).

É lugar-comum o argumento de que um Judiciário que funciona bem serve de contrapeso aos outros poderes governamentais, provendo garantias para a separação entre os poderes e para a proteção das minorias (Madison, Hamilton e Jay, 1961; Montesquieu, 1990). No entanto, o Judiciário é inerentemente passivo e precisa ser acionado por atores externos para que tenha qualquer efeito. Por isso, o grau com que o Judiciário é invocado para servir como árbitro nos conflitos entre as forças ou instituições políticas depende não apenas da força dos tribunais, mas também, de forma mais abrangente, dos padrões da disputa política (TAYLOR, 2007, p. 231).

$\mathrm{O}$ papel de proteção às minorias é capaz de garantir o bom funcionamento de políticas públicas, porém como esse papel só pode acionado por atores externos, torna o judiciário limitado nesse processo. Sadek (2010) vislumbra sobre essa situação ao trazer os dados da Pesquisa Nacional por Amostra de Domicílios (PNAD), publicada em 1988, indicam que, do total de pessoas envolvidas em algum tipo de conflito no ano anterior, 55\% não procuraram o judiciário. A autora 
destaca esse fato, na medida em que "indica tanto que muitos problemas não vêm sendo resolvidos pela instituição encarregada de fazê-lo, como que outros canais podem estar ocupando este espaço" (SADEK, 2010, p.5).

Tal desmotivação na procura pelo judiciário pode estar ancorada na descrença de sua eficiência, visto que muitos brasileiros apresentam o discurso que a justiça não é justa, no momento em que não é ameniza as desigualdades sociais e, principalmente, econômicas. Conforme Sadek (2010, p.9), esse reduzido percentual na utilização gratuita da justiça contribui para "propagar a imagem popular que se tem da justiça - uma justiça cara, elitista, feita para os ricos, para os que têm posse".

\section{Construção de UHES e o marco regulatório}

Os avanços tecnológicos, a busca por confortos e as metas de desenvolvimento econômico e social implicam em uma crescente demanda de energia. A universalização do consumo de energia e a crise do petróleo dos anos de 1970 instigaram a busca por fontes renováveis de energia. O Brasil possui potencial para a exploração dessas fontes, tais como hidrelétrica, biomassa, eólica, solar, biogás, geotérmica e mar, e também das fontes não renováveis, como gás natural, derivados de petróleo, energia nuclear e carvão mineral. No país, 65,2\% da matriz elétrica corresponde à fonte hidrelétrica, segundo a Empresa de Pesquisa Energética (EPE, 2018).

Para Benincá (2011, p.29), a história do setor energético brasileiro pode ser dividida em quatro períodos, o primeiro seria da Proclamação da República, em 1889, à Revolução de 1930, "quando a economia brasileira se caracterizava pela produção primário-exportadora e a energia estava baseada em fontes vegetais".

De 1930 a 1945, seria o segundo período do setor elétrico, “quando o país deu seus primeiros passos rumo à estruturação de uma política energética, o que ocorreu em função do início do processo de industrialização" (BENINCÁ, 2011, p. 29). Em 1934 foi promulgado o Código de Águas $^{15}$ que, pela primeira vez, vai estabelecer regras para o uso da água e para a produção e fornecimento de energia elétrica, pelo qual as águas pertenciam ao Estado e poderiam ser exploradas através de concessões.

A terceira fase compreenderia de 1945 ao final da década de 1980, "fase marcada pela intervenção direta do Estado sobre o setor energético” (BENINCÁ, 2011, p.30). Segundo

15 Código de Águas (Decreto Federal no 24.643, de 10 de julho): Art. 139. O aproveitamento industrial das quedas de águas e outras fontes de energia hidráulica, quer do domínio público, quer do domínio particular, far-se-há pelo regime de autorizações e concessões instituído neste Código. 
Rocha (2012, p. 75), “entrando na década de 1980, o setor hidrelétrico brasileiro se consolidou através da articulação industrial de três segmentos: estudos e projetos, construção civil e equipamentos elétricos".

Em 1987, a Resolução $n^{0}$ 006/1987 ${ }^{16}$, do Conselho Nacional de Meio Ambiente (CONAMA), regulou o processo de licenciamento ambiental dos empreendimentos hidrelétricos de grande porte, que deve ser solicitado ao Instituto Brasileiro do Meio Ambiente e dos Recursos Naturais Renováveis (IBAMA), compondo-se de várias fases (MORAIS, 2013). O processo de licenciamento ambiental possui três etapas distintas: Licenciamento Prévio, Licenciamento de Instalação e Licenciamento de Operação.

A licença prévia (LP) deve ser solicitada ao IBAMA na fase de planejamento da implantação, alteração ou ampliação do empreendimento. Essa licença não autoriza a instalação do projeto, e sim aprova a viabilidade ambiental do projeto e autoriza sua localização e concepção tecnológica. Além disso, estabelece as condições a serem consideradas no desenvolvimento do projeto executivo (GONZÁLEZ, 2012, p. 107). O licenciamento prévio é marcado pela discussão acerca das vantagens e desvantagens da obra para a região, o que acontece principalmente através da ação de mediadores no sentido de promover a identificação dos atingidos com seus respectivos projetos políticos (ROCHA, 2012, p. 62).

A licença de instalação (LI) autoriza o início da obra ou instalação do empreendimento. O prazo de validade dessa licença é estabelecido pelo cronograma de instalação do projeto ou atividade, não podendo ser superior a seis anos (GONZÁLEZ, 2012, p. 108). As discussões que até então estavam voltadas para o aspecto geral do projeto e variáveis coletivas da condição de atingido, vão gradativamente sendo permeadas por discussões mais pontuais, e as variáveis individuais vão ganhando destaque à medida que a obra se insere de fato na região em questão. Podemos dizer que este é o período de maior efervescência da discussão sobre a condição de atingido por barragem, por ser o momento em que se definem os destinos dos atingidos tendo em vista a concretização ou não da obra (ROCHA, 2012, p. 64).

A licença de operação (LO) deve ser solicitada antes de o empreendimento entrar em operação, pois é essa licença que autoriza o início do funcionamento da obra/empreendimento. Sua concessão está condicionada à vistoria a fim de verificar se todas as exigências e detalhes técnicos descritos no projeto aprovado foram desenvolvidos e atendidos ao longo de sua instalação e se estão de acordo com o previsto nas LP e LI (GONZÁLEZ, 2012, p.108). O licenciamento de operação

16 Disponível em <http://www.mma.gov.br/port/conama/legiabre.cfm?codlegi=57>. Acesso em: 15 jul. 2015. 
encaminha o processo de instalação de uma hidrelétrica para o seu final. A condição de atingido por barragem não é necessariamente superada com o início da operação da usina e a indenização ou remanejamento da população (ROCHA, 2012, p. 64).

Segundo Benincá, a quarta fase compreende o início na década de 1990 até os dias atuais, "quando se consubstancia o Plano Nacional de Energia Elétrica baseado na implantação de grandes hidrelétricas e se aprofunda o modelo neoliberal associado ao processo de privatização do setor elétrico" (BENINCÁ, 2011, p. 30). Com o Programa Nacional de Desestatização (PND) (Lei $\mathrm{n}^{\circ}$ 8.031, de 12 de abril de 1990), criado pelo presidente Fernando Collor de Mello, em 1990, a energia ficou sob o controle de poucas empresas transnacionais. Entre 1990 e 2002, pelo relatório do Banco Nacional de Desenvolvimento Econômico e Social, o BNDES, (2002, p.4), o setor elétrico teve participação de $31 \%$ na transferência de capital estatal para capital privado. $\mathrm{O}$ programa de privatização, criado no início do governo Collor, foi mantido em sua essência nos governos que o sucederam, de Itamar Franco e de Fernando Henrique Cardoso. Em 1993, o Decreto $\mathrm{n}^{\mathrm{o}} 915^{17}$ autorizava a formação de consórcios para geração de energia elétrica. As Leis $\mathrm{n}^{\mathrm{o}} 8.987^{18} \mathrm{e}$ $9.074^{19}$, de 1995, regulamentavam o regime de concessão das obras e serviços públicos a empresas privadas. Em 1996, foi instituída a Agência Nacional de Energia Elétrica (ANEEL), através da Lei $\mathrm{n}^{\mathrm{o}} 9.427^{20}$, uma autarquia ligada ao Ministério das Minas e Energia, com a finalidade de regular e fiscalizar a produção, transmissão, distribuição e comercialização de energia elétrica, em conformidade com as políticas e diretrizes do governo federal.

Com essa legislação o Estado assume, definitivamente, a condição de parceiro da iniciativa privada na instalação de hidrelétricas. No governo do presidente Luiz Inácio Lula da

17 Decreto no 915 de setembro de 1993 - Autoriza a formação de consórcios para geração de energia elétrica.

18 Lei no 8.987 de fevereiro de 1995 (Dispõe sobre o regime de concessão e permissão da prestação de serviços públicos previsto no art. 175 da Constituição Federal, e dá outras providências). Art. $2^{\circ}$ III - concessão de serviço público precedida da execução de obra pública: a construção, total ou parcial, conservação, reforma, ampliação ou melhoramento de quaisquer obras de interesse público, delegada pelo poder concedente, mediante licitação, na modalidade de concorrência, à pessoa jurídica ou consórcio de empresas que demonstre capacidade para a sua realização, por sua conta e risco, de forma que o investimento da concessionária seja remunerado e amortizado mediante a exploração do serviço ou da obra por prazo determinado.

19 Lei n ${ }^{\circ} 9.074$ de julho de 1995 (Estabelece normas para outorga e prorrogações das concessões e permissões de serviços públicos e dá outras providências). Art. $1^{\mathrm{o}} \mathrm{V}$ - exploração de obras ou serviços federais de barragens, contenções, eclusas, diques e irrigações, precedidas ou não da execução de obras públicas.

20 Lei n ${ }^{\circ} 9.427$ de dezembro de 1996 (Institui a Agência Nacional de Energia Elétrica - ANEEL, disciplina o regime das concessões de serviços públicos de energia elétrica e dá outras providências). Art. $2^{\circ}$ A Agência Nacional de Energia Elétrica - ANEEL tem por finalidade regular e fiscalizar a produção, transmissão, distribuição e comercialização de energia elétrica, em conformidade com as políticas e diretrizes do governo federal. 
Silva, foi ratificada através da Lei $\mathrm{n}^{\mathrm{o}} 11.079^{21}$, de 30 de dezembro de 2004, a qual estabelece as normas gerais para as PPP, sendo que os projetos de grande escala como as hidrelétricas passam a ser conduzidos por Sociedades de Propósitos Específicos (SPE), que têm sua criação em virtude da obra (usina) que pretendam instalar e operar (ROCHA, 2012, p.76).

Além disso, em 2007 o Brasil lança o Programa de Aceleração do Crescimento (PAC), que teria como objetivo acelerar a economia e a modernização tecnológica, aumentando a competitividade do Brasil e promovendo a integração interna do país bem como com seus vizinhos e com o mundo através de cinco blocos de medidas: investimento em infra-estrutura (onde o orçamento maior cabe ao setor energético), estímulo ao crédito e ao financiamento, (como se percebeu no caso da UHE Foz do Chapecó, obra do PAC), melhora do ambiente de investimento, medidas fiscais de longo prazo e desoneração e aperfeiçoamento do sistema tributário (VERDUM, $2007^{22}$ apud ROCHA, 2012, p. 132).

Com a mudança de governo não se efetivaram todas as medidas necessárias à implementação do modelo de reforma de Estado e de marco regulatório proposto no governo Fernando Henrique Cardoso, porém o governo Lula tampouco conseguiu realizar mudanças profundas na estrutura jurídica legada pelo antecessor. Assim, o modelo brasileiro de geração, transmissão e distribuição de energia elétrica acabou tornando-se um híbrido entre os setores privados regulados por um sistema de agências autônomas e atividades executadas diretamente por empresas públicas e pela administração direta que, em que pese estejam nominalmente sob o mesmo regime jurídico, gozam de uma autonomia muito maior em razão de fatores políticos (GONZÁLEZ, 2011, p. 102).

\section{Exploração da bacia do Rio Uruguai}

A região da bacia do rio Uruguai é favorável para a exploração hidrelétrica devido ao relevo acidentado, compreendendo vales e serras ao longo do leito do rio e seus afluentes. Segundo Boamar (2003, p. xvii), a bacia do rio Uruguai transformou-se no final do século XX e início do século XXI em um imenso canteiro de obras $^{23}$ e foi nas últimas décadas um campo aberto de conflitos econômicos e sociais: de um lado os benefícios transitórios, que ocorreram durante as

21 Lei n 11.079 de dezembro de 2004 - Institui normas gerais para licitação e contratação de parceria público-privada no âmbito da administração pública.

22 VERDUM, Ricardo. Obras de infra-estrutura no contexto da integração Sul-Americana. In: (Org.). Integração, usinas hidroelétricas e impactos socioambientais. Brasília: INESC, 2007.

23 "Diante do exposto, percebemos que o argumento da "vocação hidrelétrica" brasileira a partir de fatores naturais (fluviosidade e relevo), encontra ainda mais preponderância no caso da bacia do rio Uruguai, tanto que já foram inventariadas 30 hidrelétricas na bacia, algumas concluídas e outras em processo de licitação, licenciamento ou instalação" (ROCHA, 2012, p 81). 
obras, como os empregos e os impostos (após as obras), verificou-se os ganhos permanentes, tais como, a compensação financeira por geração de energia elétrica e o turismo, por outro lado, diversos problemas sociais e econômicos ocasionados pelas obras de implantação nas regiões.

Os primeiros levantamentos dos recursos energéticos da bacia do rio Uruguai foram realizados pelo Comitê de Estudos Energéticos da Região Sul, ENERSUL, entre os anos de 1966 e 1969, através de um inventário da região. Estes trabalhos contaram com a supervisão técnica do consórcio Canadense-Americano-Brasileiro (CANAMBRA Engineering Consultants Limited) e abrangeu as bacias hidrográficas dos estados do Rio Grande do Sul, Santa Catarina e Paraná. Em 1968, as iniciativas governamentais para a construção de UHEs continuaram com a contratação de estudos preliminares e a fundação da ELETROSUL, em 1968, companhia estatal responsável pelo setor de produção energética do Sul do país. A ELETROSUL realizou o estudo sobre a possibilidade de construção de UHEs nessa região, e em 1979, publicou a revisão do inventário hidroelétrico da bacia do Rio Uruguai, que apresentava a possibilidade de construção de 22 UHEs nacionais nessa bacia (MORAIS, 2013).

As primeiras barragens nacionais, Machadinho e Itá, foram autorizadas para a construção em 1982. Segundo os dados da Cartilha do rio Uruguai (2006, p. 24-32), 30 UHEs já foram inventariadas no rio Uruguai e seus afluentes: Barra do Pessegueiro, São Roque, Garibaldi, Campos Novos, Passo da Cadeia, Pai Querê, Barra Grande, Machadinho, Itá, Monjolinho, Passo Fundo, Aparecida, Abelardo da Luz, São Domingos, Quebra-Queixo, Gabiroba, Bom Jesus, Xanxerê, Voltão Novo, Foz do Chapecozinho, Nova Erechim, Foz do Chapecó, Itapiranga, Roncador, Complexo Hidrelétrico Garabi (Garabi, São Javier e Santa Rosa), Passo São João, São José, São Pedro/ Monte Caseiros, Salto Grande e Fray Bentos. Com as consessões nas mãos da iniciativa privada, a partir da década de 1990 foram concluídas cinco UHEs, dessas que já foram inventariadas, no trecho brasileiro do rio Uruguai: Itá (1999), Machadinho (2001), Barra Grande (2006), Campos Novos (2008) e Foz do Chapecó (2010). A seguir são identificados um dos atores (considerando os elementos indispensáveis para o processo de tomada de decisão apontados por Campos, 2001) que tem interesse na decisão a ser tomada pelos atingidos: os empreendedores das UHEs implantadas na bacia do rio Uruguai.

\section{Remanejamentos e o Judiciário}

Percebe-se que há um marco regulatório para a construção de UHEs no Brasil, que garante a implantação desse empreendimento perante o Estado, que é parceiro público dessa PPP do 
setor elétrico. Porém, não está bem definido um marco regulatório capaz de garantir uma negociação justa e igualitária para o remanejamento dos atingidos. Tal dificuldade começa pela posição do Estado nessa negociação, na qual, mesmo que o atingido resista à negociação, em algum momento será desapropriado em nome de um bem público: a água que garante a energia que leva ao desenvolvimento econômico.

Rocha (2012) destaca que os empreendedores recorrem à justiça, quando a obra, por algum motivo, é embargada, alegando legitimidade da sua demanda.

Os donos do dinheiro, por si, não conseguiriam desenvolver as ações de expropriação descritas anteriormente, porém, com a regulação legal do trabalho e da propriedade pelo Estado, esse processo ganhou a legalidade necessária e ante a mobilização dos expropriados, inclusive através de tentativas legais via parlamento, outro aspecto do processo de acumulação entrou em cena, a dizer, o judiciário, que se prontificou para enquadrar as ações dos trabalhadores naquela oportunidade como "conspiratórias" (ROCHA, 2012, p.46).

Deve-se reconhecer que a condição de atingido vem sendo ampliada significativamente pelas negociações e pressões homologadas judicialmente, que garantem o debate sobre quem é ou na atingido. Porém, torna-se necessário listar algumas (poucas, pois variadas são as vivências dessas famílias desde o comunicado de que terão que sair de suas casas até o momento de serem, justamente, indenizados) das circunstâncias vivenciadas pelos atingidos que demonstram o judiciário como um suporte ao Estado e ao empreendedor nos remanejamentos:

1. os processos de negociação acerca da compra e indenização de propriedades imobiliárias e benfeitorias se realizam sob a ameaça da desapropriação judicial;

2. caso a família atingida não concorde com os valores ofertados pela sua propriedade, tem o direito de acionar judicialmente o consórcio. Tal conflito é protagonizado, de um lado, pelo grupo de empresas privadas e estatais, com um amplo corpo jurídico, além de recursos financeiros para manter a disputa judicial por longo tempo, a outra parte corresponde a uma família, que, na maioria dos casos na bacia do rio Uruguai, detém uma pequena área de terra que é a sua única fonte de sustento, o que agrava a urgência pela resolução, já que disto depende a reprodução do seu modo de vida (ROCHA, 2012);

3. é comum que empresas se prevaleçam do ato declaratório da utilidade pública para impor preços e condições de venda desfavoráveis;

4. que vige, desde o Estado Novo, o Decreto-lei 3365/41, cujo artigo $9^{\circ}$, ao vedar ao poder judiciário decidir a existência ou não da utilidade pública para efeitos de desapropriação, 
confronta com o disposto no artigo 5o, inciso do XXXV da CF, que determina que "a lei não excluirá da apreciação do poder judiciário lesão ou ameaça a direito" (Relatório da Comissão Especial Atingidos por Barragem, s/d);

5. que os casos que chegam à justiça não têm encontrado tempestiva resposta do Judiciário, configurando a demora que constitui, ela mesma, uma nova e específica violação, inclusive por propiciar a consolidação da violação denunciada (Relatório da Comissão Especial Atingidos por Barragem, s/d).

Tais situações acabam com a lógica de proteção das minorias do judiciário nessa situação das UHEs, visto que o mesmo não é um canal alternativo na busca por justiça e quando é, não dá o retorno esperado pelo atingido, sendo porque o interesse maior é do Estado ou porque legalmente os processos demoram e o atingido acaba por desistir.

É interessante trazer para este artigo a fala de dois atingidos por UHEs, para que seja factível ir ao encontro da fala de Sadek de que a população não procura o judiciário pela morosidade e elitização desse poder. Primeiro atingido ressalta que:

Eu acabei aqui por que eles chegaram assim: "Darci ou tu pega o dinheiro ou tu vai parar na justiça". Eu dizia: "eu só troco por 33 [hectares de terra]". Eu fiz a proposta, eles [FCE] não aceitaram. Daí, eles me pagaram o que eu tinha em cima e mais ou menos uns 10 [hectares], mas ficou 23 hectares pra trás. A questão é essa: essa terra não era aquela terra que a gente tinha lá por isso que a gente queria a troca de terra. [...] Eu não tinha terra pra vender, eu não queria dinheiro. E com aquele valor nós não conseguimos comprar os 33 ha. [...] Na justiça foi mais de dois anos. [...] A gente pegou advogado, mas daí eu tive que gastar com advogado. Daí eu consegui recuperar 30 mil [reais] em cima da área. Daí eu vi que era pouco ainda, mas eu achei que nós tinha que acertar porque [...] o juiz falou que de repente se nós não se acertasse ali, nós ia ter que pegar um outro técnico pra fazer um novo levantamento, pagar daí de novo, né. Daí, acabamo acertando (apud ROCHA, 2012, p.289).

Complementando essa entrevista, outro atingido, reforça que "eu fui na justiça, mas desisti porque a justiça não ajuda essa parte ai da negociação com empresa de barragem, não adianta. Eu botei e sai fora, e quem botou na justiça tá lá até hoje” (apud ROCHA, 2012, p.190). Tais declarações demonstram que o judiciário está em descrédito, apesar de ter feito conquistas significativas na ampliação do conceito de cidadão atingido. Também é possível confirmar tal descrédito pelos dados do survey aplicado com 632 famílias atingidas na bacia do rio Uruguai pelo projeto P\&D Remanejamento, pois 57,6\% dos atingidos não confiam no judiciário (PASE, 2012). A maioria dos cidadãos atingidos não confia no judiciário, por conseqüência não o procura para tentar 
equilibrar essa relação de poder travada com o Estado e o empreendedor. Nessa situação dos remanejamentos, é complicada a especulação do motivo, porém parece que muitos podem ser os fatores, entre eles: falta de informação dos direitos, medo de retaliações por parte dos empreendedores, receio de um posicionamento do judiciário a favor do Estado e do empreendedor, pressão pelo tempo que o processo poderá demorar e, principalmente, por não confiar no judiciário.

O objetivo desse artigo era verificar o papel do judiciário nos remanejamentos, porém tal papel só pode ser exercido pelo acionamento desse poder. Tal situação não acontece na maioria dos casos, e quando acontece o judiciário traz a tona os entraves desse processo, demorando com seu julgamento e tornando caro para o atingido manter essa luta por justiça.

\section{Considerações Finais}

O processo de remanejamento de famílias atingidas por UHEs de fato é complexo. Principalmente por incluir atores sociais com interesses completamente opostos, sendo um dos principais o Estado com a bandeira de desenvolvimento econômico.

O judiciário apresentou progressos ao ampliar o conceito de atingido, através das ações judiciais promovidas pelos cidadãos e pelo Movimento dos Atingidos por Barragens. Porém não é um ator de muita confiança para os cidadãos atingidos, visto que os processos movidos no âmbito das negociações não apresentaram grandes progressos para o lado mais fraco dessa disputa: o atingido.

O artigo não apresenta conclusões contundentes, mas evidencia que um papel mais ativo do judiciário é de extrema importância. Porém até que ponto, essa ampliação do papel judiciário no processo de remanejamentos, garantiria mais igualdade nessa relação de poder estabelecida entre Estado/empreendedor e o cidadão atingido? Tal questão surge para instigar novos trabalhos nessa área, que tenham o objetivo de contribuir para a formulação de um futuro marco regulatório dos remanejamentos.

\section{Referências}

BENINCÁ, Dirceu. Energia \& Cidadania: a luta dos atingidos por barragens. Editora Cortez, São Paulo, 2011.

BNDES. Relatório Anual do Banco Nacional de Desenvolvimento 2002. Disponível em: $<$ http://www.bndes.gov.br/SiteBNDES/bndes/bndes_pt/Institucional/Relacao_Com_Investidores/ Relatorio_Anual/RelAnual2002.html>. Acesso em: 15 jul. 2015. 


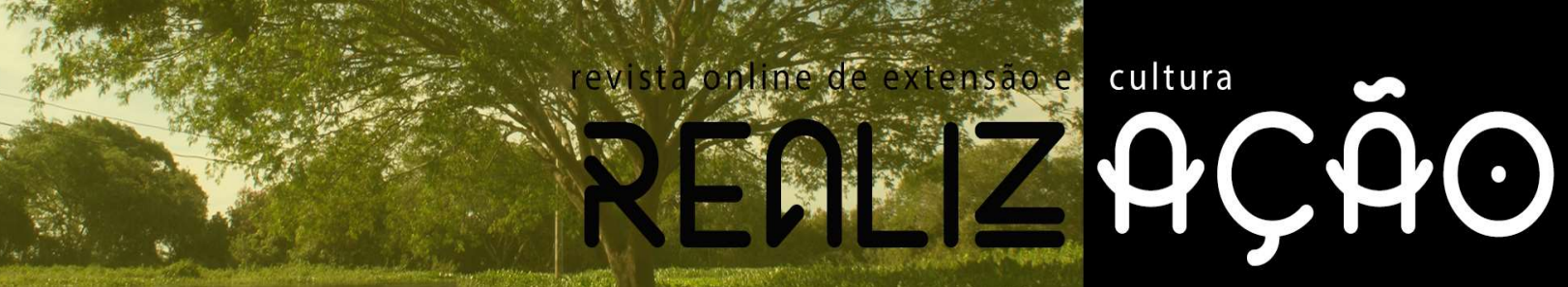

BOAMAR, Paulo. A implantação de empreendimentos hidroelétricos: o caso da UHE de Machadinho. Dissertação de Mestrado em Engenharia de Produção, Univeridade Federal de Santa Catarina: Florianópolis, 2003.

CARTILHA DO RIO URUGUAI. Hidrelétricas na bacia do rio Uruguai. 2006. Disponível em: $<$ http://www.natbrasil.org.br/Docs/cartilha_rio_uruguai.html $>$. Acesso em: 15 jul. 2015.

CASTRO, Marcos Faro de. O Supremo Tribunal Federal e a judicialização da política. RBCS, 34, 2009. Disponível em: <www.anpocs.org.br/portal/...00.../rbcs34_09.htm>. Acesso em: 21 mar.2018.

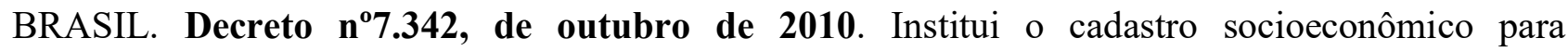
identificação, qualificação e registro público da população atingida por empreendimentos de geração de energia hidrelétrica, cria o Comitê Interministerial de Cadastramento Socioeconômico, no âmbito do Ministério de Minas e Energia, e dá outras providências. Disponível em: $<$ http://www.planalto.gov.br/ccivil_03/_Ato2007-2010/2010/Decreto/D7342.htm>. Acesso em: 04 jul. 2018.

EPE. Balanço Energético Nacional - Relatório Síntese | ano base 2017 - Empresa de Pesquisa Energética. 2018. Disponível em: <http://www.epe.gov.br/pt/abcdenergia/matriz-energetica-eeletrica >. Acesso em: 02 abr. 2019.

FALLETI, Tulia. Efeitos da Descentralização nas Relações Intergovernamentais: o Brasil em perspectiva comparada. In: SOUZA, Celina; NETO, Paulo Fábio Dantas (org.). Governo, Políticas Públicas e elites políticas nos estados brasileiros. 2006. Rio de Janeiro, Revan.

FERNANDeS, Antônio. Políticas Públicas: Definição, Evolução e o Caso Brasileiro. s/d. Disponível em: <http://serv01.informacao.andi.org.br/b6d71ce_114f59a64cd_-7fcc.pdf $>$ Acesso em: 14 mai. 2018.

GONZÁLEZ, Rodrigo Stumpf. O marco regulatório do setor elétrico no Brasil. In: PASE, Hemerson Luiz; BAQUERO, Marcello (org.). Estado, democracia e hidroeletrecidade no Brasil. Editora Universidade UFPEL, Pelotas, 2012.

GRINOVER, Ada Pellegrini. O controle das políticas públicas pelo Poder Judiciário. Revista do Curso de Direito da Faculdade de Humanidades e Direito, v. 7, n. 7, 2010, p. 10-37. Disponível em: $\quad<$ https://www.metodista.br/revistas/revistas-ims/index.php/RFD/article/viewFile/1964/1969>. Acesso em: 21 mar. 2018.

MORAIS, Jennifer Azambuja de. O processo de tomada de decisão dos cidadãos atingidos por usinas hidrelétricas. Dissertação de Mestrado do Programa de Pós-Graduação em Ciência Política, Universidade Federal de Pelotas. 2013.

PASE, Hemerson. Survey. Pesquisa Avaliação dos Resultados e Proposição de Modelo de Elaboração de Programas de Remanejamento da População Atingida por Empreendimentos Hidrelétricos (2010-2014). 2012. 
